\title{
O CONSUMO DE MEMES COMO FORMA DE MINIMIZAÇÃO DA ANSIEDADE EM JOVENS ADULTOS NO BRASIL
}

\author{
Mariane Nascimento Reis
}

UNISANTOS

\begin{abstract}
RESUMO
Este trabalho tem como objetivo compreender como os memes humorísticos da internet, compartilhados por jovens adultos (adultos emergentes) podem contribuir para a amenização do sentimento ansioso vivenciado por esta população, especialmente no momento pandêmico de Covid-19. Para esse fim, a metodologia empregada foi a de pesquisa qualitativa de cunho exploratório, por meio de dados bibliográficos e levantamento documental, de memes na internet, e uma análise qualitativa de cunho psicanalítico. Com a iminência pandêmica, a coleta de dados sobre o tema se tornou mais ampla. Os resultados apontam que o jovem adulto está propenso a sentir-se ansioso pela percepção do que seria a vida adulta e das exigências da sociedade. As redes sociais e os laços que se formam, podem contribuir para que encontrem um espaço de compartilhamento de suas vivências e angústias, que podem ser sintetizadas por meio da linguagem dos memes. Os memes têm como característica a utilização do humor para retratar a mensagem vinculada. O humor pode ser entendido como um meio de expressão e sua função, psicanaliticamente, de amenizar uma situação sofrível, assim, como em uma pandemia. Consequentemente, o humor nos memes e seu compartilhamento evidencia um processo de afastamento do sofrimento e demonstra experiências e significados compartilhados de um grupo social.
\end{abstract}

Palavras-chave: Jovem Adulto; Ansiedade; Humor; Internet. 


\section{ABSTRACT}

\section{MEMES CONSUMPTION AS A FORM OF MINIMIZING ANXIETY IN YOUNG ADULTS IN BRAZIL}

This work aims to understand how the humorous memes of the internet, shared by young adults can contribute to the easing of the anxious feeling experienced by this population. For this purpose, the methodology used was that of qualitative research of an exploratory nature, through bibliographic data and documentary survey, of memes on the internet, and a qualitative analysis of a psychoanalytical nature. The results indicate that the young adult is prone to feel anxious about the perception of what adult life would be and the demands of society. Social networks and the bonds that are formed can contribute to finding a space for sharing their experiences and anxieties, which can be synthesized through the language of memes. Memes are characterized by the use of humor to portray the linked message. Humor can be understood as a means of expression and its function, psychoanalytically, to alleviate a suffering situation. Consequently, the humor in memes and their sharing shows a process of moving away from suffering and demonstrates shared experiences and meanings of a social group.

Keywords: Young Adult; Anxiety; Humor; Internet. 


\section{INTRODUÇÃO}

O cenário da sociedade moderna atual se caracteriza pelas exigências sociais, transformações em ritmo acelerado e um futuro incerto. Diante disso, muitos jovens adultos vivem este estágio da vida como um momento de inconstâncias, de explorações e exigências. Logo, os sentimentos de insuficiência, desamparo e ansiedade tendem a surgir. Segundo o estudo da Organização Pan-Americana de Saúde (2017) os jovens estão entre a população mais ansiosa e alerta que pode a vir a aumentar ao longo dos anos.

Os meios tecnológicos de comunicação podem ser um meio para compreender, conhecer e acessar os sentimentos despertados nos jovens. A internet é um veículo de livre expressão e uma forma de comunicação encontrada é por meio de compartilhamentos de materiais digitais como os memes. Os memes transmitem uma mensagem que muitas vezes, estão embutidos de humor visto como uma outra forma de expressar, compreender a realidade e, psicanaliticamente, pode ser um meio de alívio e leveza diante das angústias.

Desse modo, a pesquisa tem como objetivo compreender como o consumo de memes humorísticos na internet, podem ser um meio de minimização do sentimento de ansiedade em jovens adultos, visto que, os jovens são a população que mais estão conectados na internet e consomem os materiais vinculados a ela, segundo a Pesquisa Nacional por Amostra de Domicílios Contínua (2017). Sendo assim, a internet pode ser o veículo que estes utilizam para expressar, compreender sua realidade e uma busca de alívio diante de uma sociedade acelerada e atravessada por muitas transformações e exigências.

\section{METODOLOGIA}

A produção partiu de uma pesquisa de natureza exploratória, que segundo Gil (2008) tem como finalidade esclarecer e desenvolver conceitos, com o objetivo de prover uma visão geral, com riqueza de informações, acerca de um determinado fato. Na primeira etapa, foi realizado o método bibliográfico, desenvolvido a partir do levantamento de dados a partir de artigos científicos e livros. Para o levantamento de dados foram utilizados palavras-chaves e seus sinônimos, entre elas: "jovem adulto", "ansiedade”, "humor", "internet”, "redes sociais", "memes", com abrangência de vinte anos, a partir da atualidade; partindo de bancos de dados eletrônicos, como Google Scholar, SciELO, ScienceDirect, Portal Capes, e em livros impressos e digitais que versam o cenário dos objetos da pesquisa. 
A segunda etapa foi realizada a partir do método documental, que é o levantamento de materiais que ainda não foram analisados, como filmes, gravações, fotografias, entre outros, neste caso, os memes da internet. A seleção dos memes foi constituída por conveniência, que segundo Gil (2008) é a seleção de materiais das quais se tem acesso, em que se admite que esses possam, de alguma forma, demonstrar ou representar a pesquisa. A busca do material se realizou durante todo o processo de elaboração do trabalho, de fevereiro a outubro de 2020 em redes sociais virtuais como Instagram, Twitter, Facebook e Google Imagens.

Foram selecionados 4 memes em sites, realizado de forma aleatória de forma como apareciam nas redes; categorizados em temas: (1) sentimento em relação ao início da vida adulta; (2) sentimento em ser adulto; (3) sentimento de ansiedade e amparo; e (4) o sentimento em relação à realidade pandêmica. A análise dos memes orientou-se pelo modelo indiciário proposto por Carlo Ginzburg, que por meio de materiais, "dados aparentemente negligenciáveis, remontar a uma realidade complexa não experimentável diretamente" (GIL, 2008, p.152). É como um detetive, como a figura do caçador, em que a partir de detalhes, muitas vezes, despercebidos que, quando decifrados e analisados, podem mostrar algo revelador.

\section{RESULTADOS}

O início da vida adulta costuma oferecer para muitos jovens uma "moratória", ou seja, um prolongamento do tempo, para que se possa ingressar na vida adulta. Nesta moratória, o jovem pode experimentar papéis sociais, estilos e formas de vida diferentes até encontrar o seu próprio e assumir suas responsabilidades e compromissos da vida adulta. Sociologicamente, um relacionamento estável e a formação de uma família, a entrada no mercado de trabalho ou a profissionalização, a independência financeira, são marcadores que definem a entrada na vida adulta. Contudo, deve-se considerar que o caminho para a vida adulta seja influenciado por diversos fatores, como o contexto social e cultural em que esse jovem está inserido, que podem adiantar ou atrasar a entrada na vida adulta (GRIFFA; MORENO, 2001; PAPALIA, FELDMAN, 2013).

Jeffrey Arnett (2004) propôs o conceito de "adultez emergente", em que abarcaria o momento da sociedade atual com o adiamento das responsabilidades adultas; seriam os marcadores sociais, juntamente com a compreensão do que é ser adulto pelos jovens. As 
características do jovem nessa fase, seriam: (1) exploração da identidade, o jovem se sente desprendido para experimentar as possibilidades identitárias; (2) instabilidade, em que muda as estratégias e os planos de vida em consequência das explorações de identidade; (3) auto centramento, antes do jovem assumir a vida adulta, aproveita para aprender sobre si e ser autossuficiente, um momento necessário antes de se comprometer; (4) sentimento de transição, o sentimento ambíguo de não ser adolescente e nem adulto, é o momento em que se dá o processo a vida adulta; (5) possibilidades, em que o jovem tem a oportunidade de se construir e transformar seu futuro, mesmo que tenha passado dificuldades anteriores (PONCIANO; SEIDL-DE-MOURA, 2017).

As exigências sociais e pessoais, os compromissos e responsabilidades da vida adulta, este momento de exploração e transição podem gerar angústia nos jovens que estão ingressando na vida adulta. Andrade et al (2019) caracterizam o termo "Ansiedade", com sua origem no latim anxius, anseio, por sua vez é derivada de agere, com a significação de agitação, angústia, e sufocamento, respectivamente. Segundo uma pesquisa da Organização Mundial da Saúde (OMS) realizada em 2015 e publicada em 2017, aponta um crescimento de 14,9\% entre 2005 e 2015 da população ansiosa; a Organização considera, que a ansiedade é uma das causas principais de incapacitação no mundo e, a Organização Pan-Americana de Saúde, alertou em 2018 sobre a incapacitação de jovens causada pela ansiedade.

Freud propôs, em 1926, com a publicação de “Inibições, sintomas e ansiedade", uma teoria sobre a ansiedade. Compreende o autor que o ser humano nasce com capacidade de reagir ao meio ambiente por meio de manifestações físicas e psicológicas, a qual denominase ansiedade. Para Freud (1926/1976), a ansiedade se encontra na instância do ego, que tem como função dominar e descarregar estímulos, que manifesta a ansiedade a fim de reagir a uma situação de perigo. Surgiria a partir da criação de sintomas, a fim de se livrar ou evitar uma situação de perigo, por isso, também, se relaciona a expectativa de um perigo, para estar preparada a ela. Sempre quando houver a possibilidade de a situação de perigo ocorrer, a ansiedade será acionada, para o autor, "a ansiedade é um produto do desamparo mental (...)" (FREUD, 1926/1976, p. 162).

Há três formas de situação de perigo que Freud (1926/1976) propõe, a situação de perigo em que se constituiu a separação de uma pessoa que é importante como fonte de satisfação é lidada como o perigo da perda de objeto, a que se segue o perigo de não ser 
amado por ela; mesmo a pessoa estando presente pode temer a perda de seu amor, a qual se refere perda do amor de objeto. A situação proveniente do perigo de castração, refere ao medo, a ansiedade de ser separado, de perder um objeto de grande valor, de brilho fálico. A ansiedade de castração conduz aos processos defensivos nas neuroses, a situação de perigo que provém do superego que repousa na ansiedade moral e social, no medo de ser punido, desaprovado, culpado ou perder o amor do superego.

Na sociedade moderna, Bauman (2007) considera que os indivíduos vivem uma vida liquida, ou seja, numa sociedade em constante transformação e rapidez em seus processos, os indivíduos vivem à mercê dessa sociedade, seguindo seu fluxo e permeada de modernização, transformação, velocidade; o que provoca nos indivíduos o sentimento de ansiedade, por se sentirem pressionados pelas exigências de acompanhar a sociedade em evolução. Por isso, segundo o autor, a vida é precária, sendo vivida em condições de incerteza; vive-se em uma "sociedade de valores voláteis, descuidada do futuro, egoísta e hedonista, onde a velocidade e não a duração é o que importa" (BAUMAN, 2007, p.10).

Macêdo (2012), aponta que na sociedade moderna há um processo de fragmentação do tecido social; que pode ser visualizada pelo abandono do Estado (referencial simbólico), que potencializa a vivência de desamparo pelos indivíduos que buscam no consumo uma estratégia de sobrevivência e preenchimento do vazio existencial, dando algum sentido em sua vida. Para a autora, o desamparo é a causa primeira dos sofrimentos, que faz emergir as psicopatologias, como ansiedade, pânico, psicossomatizações; pelos laços frágeis e descartáveis, pela dissimetria entre as exigências sociais e os meios para cumpri-las, pela falta de um referencial simbólico, pelo consumismo exacerbado.

Desse modo, para os jovens, cada um encontrará alguma forma para lidar com os sentimentos angustiantes e de estresse, que são comuns neste período de mudanças; que podem ir de comportamentos saudáveis para os não saudáveis, podendo afetar a saúde física e mental. Uma das formas em que o jovem pode lidar com as situações estressoras que Ihe surgem seria por meio das relações sociais, que apresentam benefícios a saúde e bem-estar, sendo um relacionamento face a face ou através de redes virtuais, que aparentam ter os mesmos benefícios e onde a maioria dos jovens também se encontram (ELLISON, STEINFIELD e LAMPE, 2007; COHEN, 2004 apud PAPALIA, FELDMAN, 2013). 
As tecnologias de comunicação interligadas por meio de redes permitiram que, através do virtual, pessoas distantes se aproximassem em espaços curtos de tempo, facilitou na produção, compartilhamento e acesso de informações; ou seja, modificou a forma de interação com o meio, com a realidade (MORAN, 1996). A comunicação via computadores foi definida por Lévy como ciberespaço, é “um espaço de comunicação aberto pela interconexão mundial dos computadores e das memórias dos computadores" (MORAN, 1999, p.92). É uma forma de explorar todos os recursos oferecidos por essas infraestruturas de modo inventivo, coletivo e interativo, a exemplo, os vários modos de comunicação, do correio eletrônico a realidade virtual, estimula uma comunicação e um estilo de relacionamento que independe da localização e do tempo.

A comunicação que é expressa na internet está relacionada a livre expressão, em todas as formas (CASTELLS, 2003). A ferramenta utilizada para a comunicação e expressão são os sites de redes sociais, como Facebook, Twitter, Blogs, entre outros. Segundo Recuero (2009), os sites de redes sociais foram definidos por Boyd \& Ellison (2007) como aqueles sistemas que permitem a construção de uma persona através dos perfis da página pessoal do site, a exposição pública do indivíduo e a interação com outros indivíduos através de comentários, curtidas, entre outros. A interação, segundo a autora, é um reflexo comunicativo influenciada pelo contexto e pelas motivações, como por exemplo, o suporte social, quando alguém escreve que está triste pode receber apoio através de comentários e se sentir melhor. O que contribui para que a interação seja geradora e/ou mantedora das relações sociais e de laços sociais.

A interação e os laços formados por meio da internet podem proporcionar aos indivíduos, um sentimento de pertencimento e de comunidade. Assim como nos espaços sem mediação digital, os indivíduos na internet buscam conexões com outros indivíduos, a partir de seus interesses, desejos e aspirações (RECUERO, 2009). A definição mais comum de comunidade mediada pelo computador, a chamada comunidade virtual é a de Barry Wellman (2008, p. 228): “comunidades são redes de laços interpessoais que proporcionam sociabilidade, apoio, informação, um senso de integração e identidade social". Entretanto, Castells (2003) aponta que as comunidades são dinâmicas na internet, construídas a partir da escolha dos indivíduos, fundamentadas na seleção do tempo, lugar e parceiros de interação. 
Os sujeitos personalizam suas redes de pertencimento de acordo com seus projetos, valores, afinidades e interesses que se modificam ao longo do tempo.

\subsection{MEMES E HUMOR}

O conceito de meme surge no livro "O Gene Egoísta", publicado em 1976 pelo etólogo Richard Dawkins. Para o autor, existe uma unidade de transmissão de informação cultural semelhante ao gene, ao que nomeou por meme. A palavra meme é a abreviação de mimeme, de raiz grega que significa imitação. Como exemplo, têm-se as melodias, os slogans, os comportamentos, as ideias, os padrões culturais, as crenças, os preconceitos. A ideia do autor é que a transmissão do meme aconteça de cérebro para cérebro de forma seletiva, ou seja, a partir de todos os acontecimentos, comportamentos ou memes que é possível imitar. Alguns serão imitados e outros não, sendo esquecidos, além dos cérebros para a transmissão dos memes, há outras formas como placas, fotografias, roupas, gestos, livros, entre outros, ou seja, qualquer artefato que possa sustentar, transportar e transmitir o meme (RECUERO, 2009; HORTA, 2015; JESUS, 2020).

Desse modo, o termo meme também denomina o fenômeno na internet, caracterizado pela propagação de informações, comportamentos, conceitos entre outros, e pela sua repetição nas redes e sites da internet. Os memes na internet, assim como na biologia de Dawkins, representam a cultura e a cosmovisão de um grupo na internet. Refletem a dinamicidade e a velocidade que a internet apresenta, com o acesso a diversas fontes de informações, o alcance global dessas informações e a forma rápida de acessá-las. A partir da ação humana de transmitir os memes por meio de sua difusão e compartilhamento, estes alcançam muitos usuários, que repetindo a ação, alcançam muitos outros. Os veículos dos memes na internet são imagens estáticas ou em movimento, vídeos, frases, brincadeiras; sua propagação ocorre em sua forma original, sendo replicada diversas vezes, ou recriadas pelos usuários, sendo este o caráter mais simbólico do meme (RECUERO, 2009; SHIFMAN, 2013; HORTA, 2015; JESUS, 2020).

O meme potencializa a vontade dos indivíduos de se expressar, de entender sua realidade, de pertencer a uma comunidade. A pesquisa, com mil entrevistados, revela que $46 \%$ dos usuários compartilham memes que traduzem seus problemas pessoais; $75 \%$ atribuem ao meme como uma forma de aliviar o estresse do dia a dia; e $64 \%$ se sentem incluídos no grupo quando entendem um meme. Na mesma pesquisa, evidencia-se que 
quanto mais jovem, mais interação há com os memes, mais de $90 \%$ dos entrevistados entre 16 a 29 anos utilizam e gostam dos memes; mas não se restringe a uma comunicação do público jovem, mas estende-se para outros públicos, entre $75 \%$ a $89 \%$ dos usuários de memes, abrange as idades de 30 a 66 anos (CONSUMOTECA, 2019).

Para Shifman (2007) atualmente a internet é o porta voz do humor. Através das ferramentas de produção e a facilidade de distribuição, é a nova fonte de expressão do humor. Pode-se encontrar na internet diversas formas e formatos do humor, mesclando fontes antigas, como charges e piadas, quanto novas, por meio de vídeos, imagens, memes. Segundo a pesquisa da Consumoteca (2019) com mil entrevistados, $85 \%$ dos brasileiros costumam gostar dos memes na internet; $57 \%$ participam de redes para acompanhar os memes; $63 \%$ procuram os memes para se distrair e $45 \%$ usam os memes para iniciar uma conversa.

Para Horta (2015) o meme apresenta a intenção de levar ao riso, através da presença do cômico e do humor. Seria uma nova forma de se entender a realidade, que demonstra um novo olhar a realidade de maneira divertida, com a liberdade de criação e associações, sem padrões rígidos. O humor propõe brincar com as experiencias e significados culturais compartilhados, cada usuário poderá se sentir representando como pode inserir e compartilhar suas experiencias. Para a autora "os memes acabaram se tornando a válvula de escape moderna para expressar a perplexidade em relação aos fatos do mundo, operando também como uma maneira de compreender esses fatos" (HORTA, 2015, p.159-60).

O significado do humor é amplo e diverso; pode ser encontrado na literatura com diversas nomenclaturas, as investigações sobre o humor são extensas e com contribuição de diversas disciplinas; que podem vir a se complementar ou se destoar. O humor é considerado um fenômeno social, com o riso partilhado no processo de comunicação; sendo, muitas vezes, definidos e partilhados dentro de uma fronteira espacial e temporal. Nas investigações sobre o humor, três teorias se destacam na explicação e na sua definição. Essas teorias tentam explicar o fenômeno do humor e na produção do riso a partir de determinadas perspectivas e técnicas. São elas, as teorias da incongruência, da superioridade e do alívio (JERÓNIMO, 2015; SALIBA, 2017).

Na teoria da incongruência, o humor está ligado à dualidade entre a percepção e a representação, ou seja, seria derivado da incongruência dessa dualidade. O humor ocorre, 
portanto, quando os indivíduos percebem que a relação entre o objeto real e seu conceito se tornaram, a partir de um ponto de vista, incongruentes. A teoria da superioridade deriva da ideia de que o humor e o riso são formas de ridículo e expressão de superioridade e hierarquia. A premissa básica dessa teoria é de grupos de mais poder ou numa posição hierárquica superior tendem a fazer piadas, a rir de grupos marginalizados, excluídos ou considerados inferiores. Na teoria do alívio, encabeçada pelos estudos de Freud (1905), o riso é uma descarga de energia psíquica que ocorre quando há uma elaboração, através da piada, de uma situação conflituosa. As piadas funcionariam como uma forma de diluir a tensão quando se trata de temas reprimidos e controversos, com o riso sendo uma forma de liberação dos desejos e pensamentos reprimidos (JERÓNIMO, 2015; SALIBA, 2017).

Freud gostava de ouvir e contar piadas, em 1905 escreveu a obra "Os chistes e sua relação com o inconsciente". O chiste é um meio de manifestar a vida psíquica, os pensamentos sexuais ou agressivos. Uma forma encontrada pelo ego para manifestar conteúdos latentes que estão inconscientes e não poderiam ser expressos por vias normais, onde seriam reprimidos; ou seja, o chiste suspende a repressão para proporcionar a descarga do conteúdo e promover prazer. O prazer deriva da economia de energia despendida para a repressão do pensamento; com o montante de energia poupado através do chiste, ela fica disponível para ser descarregada na forma do riso (BRENNER, 1975; MEZAN, 2005). Segundo Mezan (2005), o humor no chiste seria o movimento de converter o desprazer em prazer, em que os pensamentos ou afetos penosos seriam substituídos; seria como se o ego dissesse "sou bom demais, ou grande demais, para me sentir atingido pelo que está me acometendo" (MEZAN, 2005, p.171-2).

Em vista disso, em 1927, Freud escreveu um ensaio intitulado "O Humor", em que retoma a discussão do prazer humorístico do chiste de 1905. Para Freud (1927/1974), o humor apresenta sua grandeza através dos processos de evitar o desprazer e sofrimento, a partir do triunfo do narcisismo e do princípio do prazer, o qual o ego se recusa a ser assolado por uma realidade opressora. $\mathrm{O}$ autor salienta que o humor seria o processo saudável que a mente encontrou para afastar os sofrimentos, dando ênfase na invulnerabilidade do ego diante da realidade e sustentar o princípio do prazer. Pode se apresentar em relação a própria pessoa (humorista) em que o outro (espectador) deriva o prazer, ou em relação a duas pessoas, em que o outro é objeto do prazer humorístico. Supõe que o ouvinte das piadas do humorista 
compartilha ou concorda com ele para que, assim se produza o humor, o riso. $\mathrm{O}$ fato mais importante do humor é sua intenção, de jogar com a realidade.

\section{DISCUSSÃO}

Ao analisar os resultados dos objetos que compõem o fenômeno pesquisado, percebese que o ciberespaço permite a comunicação e a expressão dos indivíduos e que traduz um momento histórico e cultural de um grupo ou comunidade. Assim, um meio de comunicação e expressão cultural na internet são os memes, muitos com teor humorístico. Desse modo, os sentimentos expressos pelos jovens podem ser visualizados através dos memes compartilhados nas redes sociais da internet. Muitos jovens compartilham memes que traduzem sua realidade, como os sentimentos em relação ao início da vida adulta; os sentimentos em ser adulto, sentimento de ansiedade e amparo, e o sentimento em relação a realidade que experimenta, como a pandemia. Categorias analisadas com memes a seguir.

\subsection{SENTIMENTO EM RELAÇÃO AO INÍCIO DA VIDA ADULTA}

Sociologicamente, os marcadores do início da vida adulta são a entrada no mercado de trabalho ou profissionalização, a independência financeira e afetiva, um relacionamento estável ou formação de uma família. Para uma sociedade, como a atual, que está em transformações em ritmos acelerados, a precarização do Estado e as exigências para desempenhar os papéis designados para o adulto, vide os marcadores sociais, exerce uma pressão sobre os jovens que podem gerar sentimentos angustiantes e de incerteza sobre si e o seu futuro.

Figura 1 - Sentimentos em relação ao início da vida adulta

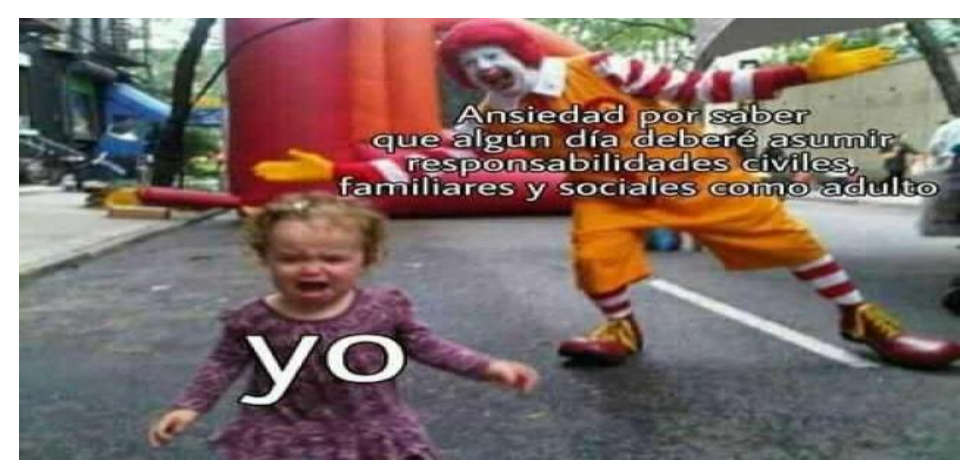

Fonte 1 - Google Imagens "Vida adulta responsabilidades memes"

O meme acima demostra através de um palhaço, que tem o papel de despertar alegria e diversão, mas em suas formas estranhas e desproporcionais podem causar espanto e medo, 
tanto que há indivíduos que têm medo de palhaço. Nesse meme, o palhaço representa a vida adulta e que não traz alegrias, mas medos de assumir as responsabilidades que lhe cabem, "responsabilidades civis, familiares e sociais" e que despertam o choro; pode ser da ameaça que estar por vir, o desamparo que sentem ao se deparar com os deveres e sentir que não conseguirá concretizá-los.

\subsection{SENTIMENTO EM SER ADULTO}

Do imaginário da vida adulta para o ser adulto. O meme que representa o estágio adulto vai de encontro com o conceito de adultez emergente, de Jeffrey Arnett (2004), em que parece que há o sentimento de não se sentir um adulto, muitas vezes, marcado pelo próprio ritmo da sociedade, como cita Bauman (2007), que se transforma de maneira tão rápida, que não oferece tempo para a consolidação do ser, da identidade do indivíduo e conseguir embarcar na vida adulta, como seria na concepção de desenvolvimento erickisiano.

Figura 2 - Sentimentos em ser adulto

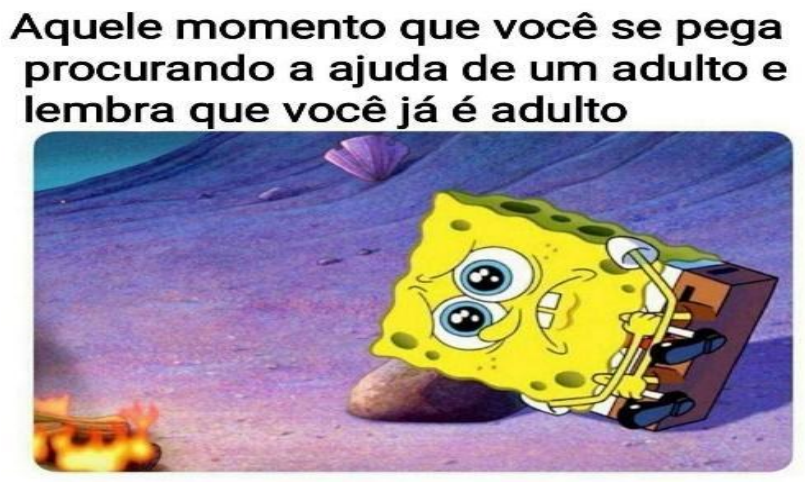

Fonte 2 - Google Imagens "Frases tristes do Bob Esponja

O meme acima demonstra a característica da adultez emergente do sentimento de transição, ou seja, o sentimento de não ser adolescente e nem adulto. Aquele momento que percebe que deverá se responsabilizar por seus atos, terá que tomar decisões por si mesmo; sem que outra pessoa, como, por exemplo, os pais se responsabilizem por seus atos. Perceber que deverá "tomar as rédeas" da própria vida, pode trazer reações, como se deduz na imagem, de apreensão e a sensação de que não conseguirá "dar conta" de suas responsabilidades, de sua vida. É a sensação de desamparo, de se ver responsável por seus fracassos e derrotas, somado com a percepção de dever de agir com a autonomia, dever de ser sozinho. A imagem associada ao texto, pode remeter, também, ao desejo do outro; para atender suas necessidades. Pode-se recordar a situação de um bebê (na posição fetal) que 
não consegue se satisfazer sozinho, necessitando do auxílio da mãe, e sem ela há a sensação do desamparo e as reações de ansiedade.

\subsection{SENTIMENTO DE ANSIEDADE E AMPARO}

Essa categoria visa demonstrar os sentimentos de desejo e expansão que os jovens sentem, os seus anseios e como uma rede de apoio se torna importante para aliviar as preocupações em torno da realização dos seus desejos. Entende-se que o jovem está em meio a possibilidades diversas que podem se transformar em exigências e lhe causar ansiedade. É a faixa etária que mais sofre com sintomas ansiosos. Mas, ao mesmo tempo, busca concretizar as suas realizações a partir de atitudes que visam para um futuro esperançoso.

Figura 3 - Sentimento de ansiedade e amparo

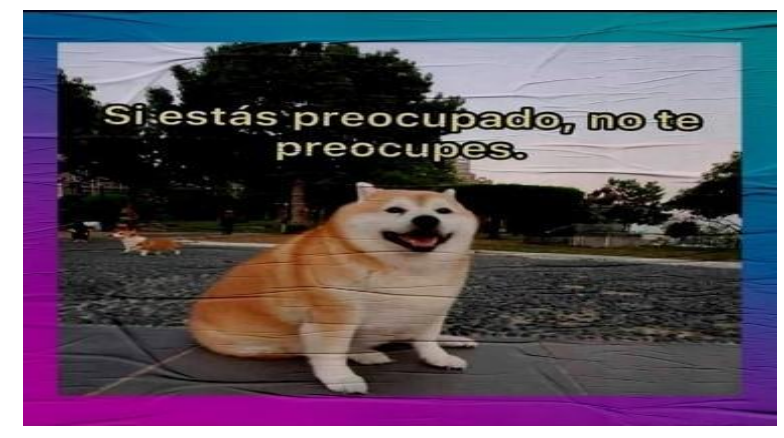

Fonte 3 - Instagram memeawards

O meme acima ilustra um animal, um cachorro, com o dizeres "se está preocupado, não te preocupes", em tradução livre. Pode-se perceber com esse meme duas teorias do humor, a incongruência e a do alívio, da psicanálise. A incongruência por usar um animal não falante, sorrindo e desejando uma despreocupação, é a dualidade entre o que é real e o que está sendo passado no meme. Na teoria do alívio e nos estudos freudianos sobre o humor, este meme traz uma dimensão libertadora, como um alívio diante de preocupações. O meme oferece, através do humor, a economia de energia. A energia que seria gasta nas preocupações, será usada no relaxamento, através do riso. E é essa a grandeza do humor que Freud se refere, mesmo com as preocupações, o indivíduo consegue não ser tão afetado por elas, rir das preocupações, mas não as negar, elas existem. O humor traz essa sensação de invencibilidade do ego, como uma forma de enfrentamento, que mesmo com as dificuldades, poderá superá-las. 


\subsection{SENTIMENTO EM RELAÇÃO A REALIDADE PANDÊMICA}

O novo coronavírus foi identificado na China, em dezembro de 2019, e logo se espalhou entre diversas pessoas e países. A Covid-19, como denominado, integra uma família de vírus, comuns em muitas espécies de animais e alguns são transmitidos a humanos. A Organização Mundial da Saúde declarou Emergência de Saúde Pública de Importância Internacional em janeiro de 2020 em virtude do surto da doença do coronavírus e alertou os a adotarem medidas para interrupção e contenção do espalhamento do vírus. Uma das medidas foi a adoção da política da quarentena, isso que significa que as pessoas tiveram seus movimentos restritos.

Brooks, et al (2020) elaboraram uma revisão sobre os efeitos psicológicos causados pela quarentena, a partir de estudos em surtos pandêmicos anteriores, apresentando como um sentimento desagradável e que provoca efeitos psicológicos negativos, como incertezas sobre a doença e duração da quarentena, sentimentos de isolamento, ansiedade, raiva, estresse, frustração e tédio. Esses sentimentos podem ser reduzidos através da ativação das redes sociais, ao contatar e se comunicar com familiares e amigos permite o apoio social, atualização de informações sobre a situação e garantam que estão bem, o que vem a reduzir esses sentimentos. A ativação da rede social, mesmo que remotamente, está associada a redução da ansiedade imediata e do sofrimento ao longo prazo.

Figura 4 - Sentimentos em relação a pandemia

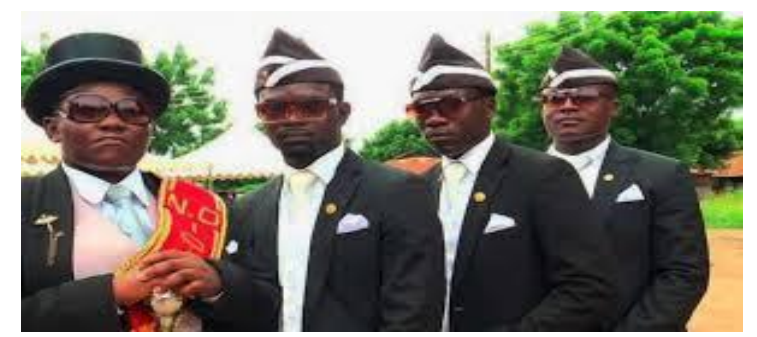

Fonte 4-Google Imagens - Meme do Caixão

O meme acima foi compartilhado durante a pandemia nas redes sociais para ilustrar os sentimentos gerados com a pandemia. Esse meme, denominado como o meme do caixão, popularizou durante a quarentena, mas, circula nas redes desde 2015 quando um vídeo de carregadores de caixão ganeses aparece dançando num funeral, a dança é uma tradição de Gana, na África. O meme é uma simbolização, ou seja, reflete, os efeitos e acontecimentos 
trágicos, a morte, que podem acontecer por meio da contaminação do vírus (MUSEU DE MEMES, 2020).

Segundo a Diretoria de Análise de Políticas Públicas da Fundação Getúlio Vargas (FGVDAPP), órgão que promove pesquisas sociais no campo de políticas públicas no Estado brasileiro, aponta que $42 \%$ das postagens nas redes sociais em fevereiro deste ano, foram referentes ao coronavírus embutidos de humor (RESENDE, 2020). Os memes seriam uma forma de suportar o estresse provocado pela pandemia, o criador da página de memes Melted Vídeos, Felipe Misale, diz que os memes representam os sentimentos vivenciados pelas pessoas e que buscam neles uma forma de encontrar respostas para o que estão vivendo (GOMES, 2020).

\section{CONSIDERAÇÕES FINAIS}

Este trabalho teve como objetivo compreender a utilização de materiais digitais humorísticos na internet como um meio de redução do sentimento de ansiedade em jovens adultos. Tal objetivo foi cumprido por meio das pesquisas bibliográficas e pela análise documental dos memes selecionados, compartilhados pelas redes sociais de internet. Foi verificado que os memes na internet conectam as pessoas por meio da mensagem que está vinculada, que é compartilhado socialmente pelas pessoas que o consomem, ou seja, elas se identificam com a mensagem.

Os memes, como Horta (2015) sugere são uma válvula de escape moderna, quando as pressões internas ou externas são muito altas, os memes recheados com humor, podem ser um caminho seguro para liberar as tensões, faz com que as pessoas se reconheçam e percebam que também é sentida por outras pessoas, não estão sozinhas, o que pode a vir a contribuir para uma minimização do desamparo, mesmo que seja temporária. Os memes demonstram a força que uma pessoa tem para conseguir enxergar além do que a realidade impõe. É a tentativa de vencer as adversidades da realidade. É a invencibilidade do ego, segundo Freud (1927/1974).

A partir das análises com os memes percebe-se que esta forma de comunicação pode ser uma forma de entender o que se passa com os grupos, com o jovem; o que eles sentem diante dos acontecimentos cotidianos e sociais. Os memes compartilhados retratam comportamentos, atitudes, situações sociais que está em comum com um grupo. Eles 
enxergam esses comportamentos com outros ângulos, utilizando o humor para questionar e refletir, além de divertir. Se tornam uma válvula, um escape de uma realidade massacrante, limitante, desgastante, podendo ser sentida como um refresco para voltar mais forte para a realidade e esperar por um futuro melhor.

Um ponto em questão do humor, além da questão do alívio e do sentimento de comunidade, pois estão compartilhando uma experiencia em comum; é a questão crítica que traz consigo. No humor e nos memes há o seu aspecto reflexivo por ter essa característica de questionar a realidade mostrando um outro aspecto dela. E uma das reflexões que este trabalho despertou é o sentido do consumo. Vemos que a sociedade moderna é baseada no consumo e os altos índices de consumo de memes por jovens e outras faixas etárias, podem estar demonstrando uma forma de preencher um vazio, o sentimento de desamparo.

Entretanto, a pesquisa sofreu limitações pela dificuldade de encontrar estudos que relacionam os memes e os fatores psicológicos. Os memes selecionados não abarcam todo o universo de memes que circulam nas redes e, consequentemente, não foi possível abarcar outros aspectos psicológicos encontrados na literatura. As reflexões não se esgotam, desse modo, se faz necessário que mais pesquisas sejam realizadas a fim de ampliar e compreender os aspectos psicológicos envolvidos no humor e na sua expressão através de conteúdos digitais, como os memes. Novas pesquisas são uma forma de ampliar os conhecimentos do fenômeno estudado, onde estão em abundância nos meios de comunicação, principalmente a internet, e que são estendidos para o cotidiano das pessoas e percebe-se que são expressão da realidade e de afetos, muito mais que apenas divertimento, o que evidencia sua importância, como um tema atual.

\section{REFERÊNCIAS}

ANDRADE, J.V. et al. Ansiedade: um dos problemas do século XXI. Revista de Saúde ReAGES, v.2, n.4, p. 34-39, jul. 2019. Disponível em: http://npu.faculdadeages.com.br/index.php/revistadesaude/article/view/220 Acesso em 27 jul. 2020

BAUMAN, Zygmunt. Vida Líquida. Trad. Carlos Alberto Medeiros. Rio de Janeiro: Jorge Zahar, 2007 
BROOKS, S.K. et al. The psychological impact of quarantine and how to reduce it: rapid review of the evidence. The Lancet v. 395, issue 10227, p. 912-920, 2020 Disponível em https://www.sciencedirect.com/science/article/pii/S0140673620304608?casa_token=HVV5 As-N-8AAAAAA:129mimyAfiTgZwPy8WyAYkfzVOSmx8h-ssaXNwZrVxFsiHaaqG451864ahB3jwwNLKtPSHvrPw Acesso em 11 mai. 2020

CASTELLS, Manuel. A Galáxia Internet: reflexões sobre a Internet, negócios e a sociedade. Trad. Maria Luiza X. de A. Borges. Zahar, 2003

CONSUMOTECA. In meme we trust. GENTE GLOBO, 29 mai. 2019. Disponível em https://gente.globo.com/meme-we-trust/ Acesso em 28 out. 2020

FREUD, S. Inibição, sintoma e ansiedade. In. Obras Completas. Trad. Christiano Monteiro Oiticica. Rio de Janeiro: Imago: 1976, vol. XX (Original de 1926)

FREUD, S. O humor. In. Obras Completas. Trad. José Octávio de Aguiar Abreu. Rio de Janeiro: Imago: 1974, vol. XXI (Original de 1927)

GIL, A.C. Métodos e técnicas de pesquisa social. São Paulo: Atlas, 2008

GOMES, T. Memes reforçam 'capacidade analgésica' do humor em tempos de pandemia. Catraca Livre, 25 mai. 2020. Disponível em https://catracalivre.com.br/saude-bemestar/memes-da-pandemia/ Acesso em 24 jul. 2020

GRIFFA, M.C.; MORENO, J.E.. Chaves para a psicologia do desenvolvimento, tomo 2: adolescência, vida adulta, velhice. Trad. Vera Vaccari. São Paulo: Paulinas, 2001

HORTA, N.B. $O$ meme como linguagem da internet: uma perspectiva semiótica. Orientador: Dr. Sérgio de Sá. 2015. 191f. Dissertação (Programa de Pós-Graduação em Comunicação) Universidade de Brasília, Brasília, 2015.

JERÓNIMO, N.A. Humor na sociedade contemporânea. Orientador: Dr. José Carlos Venãncio. 2015. 268f. Tese para obtenção do Grau de Doutor em Sociologia. (Ciências Sociais e Humanas) - Universidade da Beira Interior, Portugal, 2015.

JESUS, A. M. R. de. Manda memes: a memética e a cultura como discurso. Elemmental, 2020 Disponível em https://elemmental.com/2020/01/21/manda-memes-a-memetica-e-acultura-como-discurso/ Acesso em 31 jan. 2020

LÉVY, P. Cibercultura. Trad. Carlos Irineu da Costa. 1o ed. São Paulo: Editora 34, 1999

MACÊDO, Kátia Barbosa. O desamparo do indivíduo na modernidade. ECOS-Estudos Contemporâneos da Subjetividade, v. 2, n. 1, p. 94-107, 2012. Disponível em http://www.periodicoshumanas.uff.br/ecos/article/view/742 Acesso em 26 set. 2020

MEZAN, R. A "ilha dos tesouros": Relendo a piada e sua relação com o inconsciente. In: SLAVUTZKY, A.; KUPERMANN, D. (Orgs.) Seria trágico... se não fosse cômico. Rio de Janeiro: Civilização Brasileira, 2005. p. 129-198

MORAN, J. Novas tecnologias e o reencantamento do mundo. Tecnologia educacional, v. 23, n. 126, 14 p. 26, 1996. Disponível em http://www.eca.usp.br/prof/moran/site/textos/tecnologias_eduacacao/novtec.pdf Acesso em 29 jun. 2020 
MUSEU DE MEMES. Meme do Caixão. 08 abr. 2020. Disponível em https://www.museudememes.com.br/sermons/meme-do-caixao/ Acesso em 12 ago. 2020

MUSEU DE MEMES. Quando o viral vira meme: a propagação do coronavírus na internet. 11 abr. 2020. Disponível em https://www.museudememes.com.br/quando-o-viral-vira-meme-apropagacao-do-coronavirus-na-internet/ Acesso em 29 jun. 2020

NOGUEIRA, L.C. A pesquisa em psicanálise. Psicologia USP, v.15, n.1-2, p.83-106, 2004 Disponível em https://www.scielo.br/j/pusp/a/nMGDnFmKgySBkGkdshtfzPg/?lang=pt Acesso em 10 abr. 2021

ORGANIZAÇÃO PAN-AMERICANA DE SAUDE. Folha Informativa - Saúde mental dos adolescentes. $2018 . \quad$ Disponível em https://www.paho.org/bra/index.php?option=com_content\&view=article\&id=5779:folhainformativa-saude-mental-dos-adolescentes\&ltemid=839 Acesso em 15 jan. 2020

$\begin{array}{llllr}\text { ORGANIZAÇÃO PAN-AMERICANA DE SAÚDE. Folha Informativa - COVID-19 (doença causada } \\ \text { pelo } & \text { novo } & \text { coronavírus). } & 2020 & \text { Disponível }\end{array}$ https://www.paho.org/bra/index.php?option=com_content\&view=article\&id=6101:covid19 \&ltemid=875\#contagio Acesso em 05 ago. 2020

PNAD Contínua. Pesquisa Nacional por Amostra de Domicílios Contínua. Acesso à Internet e à televisão e posse de telefone móvel celular para uso pessoal 2017. IBGE. 2018. Disponível em https://biblioteca.ibge.gov.br/visualizacao/livros/liv101631_informativo.pdf Acesso em 10 jul. 2020

PAPALIA, D.E.; FELDMAN, R.D. Desenvolvimento Humano [Recurso Eletrônico] Trad. Carla Filomena Marques Pinto Vercesi et al. 12ㅇe ed. Porto Alegre: AMGH, 2013

PONCIANO, E. L. T.; SEIDL-DE-MOURA, M. L. Narrativas sobre si mesmo e o futuro na adultez emergente: critérios subjetivos e marcadores sociais. Psicol. Am. Lat., México, n. 29, p. 128146, dez. 2017.2 Disponível em http://pepsic.bvsalud.org/scielo.php?script=sci_arttext\&pid=S1870$350 \times 2017000300009 \&$ Ing=pt\&nrm=iso. Acesso em 07 ago. 2020

RECUERO, R. Redes sociais na internet. Porto Alegre: Sulina, 2009

RESENDE, L. Avanço do coronavírus faz Twitter diminuir memes sobre o tema e ficar mais sério. CNN Brasil, Rio de Janeiro, 18 mar. 2020. Disponível em https://www.cnnbrasil.com.br/tecnologia/2020/03/18/avanco-do-coronavirus-faz-twitterdiminuir-memes-sobre-o-tema-e-ficar-mais-serio Acesso em 28 set. 2020

SALIBA, Elias Thomé. História cultural do humor: balanço provisório e perspectivas de pesquisas. Revista de História (São Paulo), n. 176, 2017. Disponível em https://www.scielo.br/pdf/rh/n176/2316-9141-rh-a01017.pdf Acesso em 15 set. 2020

SHIFMAN, Limor. Humor in the age of digital reproduction: Continuity and change in internetbased comic texts. International Journal of Communication, v. 1, n. 1, p. 23, 2007. Disponível em https://ijoc.org/index.php/ijoc/article/view/11 Acesso em 13 out. 2020

SHIFMAN, Limor. Memes in a digital world: Reconciling with a conceptual troublemaker. Journal of computer-mediated communication, v. 18, n. 3, p. 362-377, 2013 Disponível em https://academic.oup.com/jcmc/article/18/3/362/4067545 Acesso em 13 out. 2020 
WELLMAN, B. Physical place and cyberplace: The rise of personalized networking. International Journal of Urban and Regional Researsh, v.25, n.2, p.227-252, 2001 Disponível em https://onlinelibrary.wiley.com/doi/abs/10.1111/1468-2427.00309 Acesso em 14 abr. 2021

WORLD HEALTH ORGANIZATION. Depression and other common mental disorders: global health $\quad$ estimates. $2017 . \quad$ Disponível em https://apps.who.int/iris/bitstream/handle/10665/254610/WHO-MSD-MER-2017.2-eng.pdf Acesso em 13 mar. 2020 